Colchester), and a list of 314 works on the Geology and Palæontology of Suffolk, together with an Index, complete the volume.

On the whole this Memoir, like most of those issued of late years by the Geological Survey, contains a large amount of dry detailed description, far from attractive to an "ordinary reader," and not at all calculated to arouse enthusiasm in the science. And yet these details may prove of great service in many ways, both practical and scientific. We are, however, informed by the Director-General in his prefatory notice to this Memoir, that the whole of the Pliocene deposits of the East of England having now been completely surreyed and published, it is intended to prepare a Stratigraphical Monograph illustrative of them. This we presume will bring out, more clearly than could otherwise be the case, the general results of the official and other work, towards the elucidation of which the Memoirs explanatory of particular maps will furnish a solid, if not very entertaining, basis.

\title{
COREFSPOINDEINCE.
}

\section{UNDERGROUND HEAT.}

SIR,-It was with much interest that I read in the September number Mr. J. S. Gardner's article upon the above subject, and the more so as it is rather a pet subject of my own. Thongh $I$ have never succeeded in throwing so much practical light upon it as $\mathrm{Mr}$. Gardner has, I ventured in an article in Belgravia as long ago as June, 1881, to forecast that the day might come when we might see "conductors of subterranean heat ramifying lite the gas pipes of a city into every house, and superseding the use of fuel." But I never, until now, found any one willing to treat the subject otherwise than as wild and visionary. With, however, the astonishing inventions and developments of machinery which every year presents to us, it would be nothing strange if a means were found of getting at this practically exhaustless supply of heat long before the finite quantity represented by our fuel reaches the beginning of its end. At a measurable distance beneath us we have hot air and bot water. Geysers, Mr. Gardner tells us, have actually been utilized for heating purposes. To make a geyser at a given spot would be only a question of money and skill, often probably not a greater undertaking than laying down an Atlantic cable; and the one undertaking would probably bring in as good dividends as the other.

Combe Raleigh Rectorx, Honiton.

W. Downes.

\section{UNDERGROUND HEAT.}

Sin,-I hare read Mr. Starkie Gardner's article in your Magazine for September, with much interest. I understand him to maintain that the surface of the earth is solid from cooling, and the centre solid from pressure, but that between the two there is a fluid stratum of no great proportionate thickness; he seems to think also that the continuity of the liquid stratum is in some degree interrupted by 
the roots of mountain chains forming ridge-shaped projections on the lower surface of the solid crust.

Perhaps it is not generally known how nearly this resembles a theory propounded by the late Mr. Hopkins of Cambridge thirty or forty years ago. He maintained that the earth is solid at the surface from cooling, and at the centre from pressure; that the solid centre is for the most part continuous with the solid crust; but that in volcanic regions there are subterranean lakes of molten matter between the two.

I speak with no authority, but I think it most probable that the earth is solid throughout, with the possible exception of small and perhaps only temporary reservoirs of lava. The fact that the lava in neighbouring craters often stands permanently at different levels, proves that they cannot be in communication with a common reservoir; and the tremulousness of the earth's surface, which the microphone reveals, seems to me to prove only that the materials composing it are elastic and slightly flexible.

Belfast, 9th Sept. 1885.

Joseph John Murphy.

MR. LYDEKKER ON ESTHONYX.

Sir,-The article in your August number by Mr. Lydekker on the identity of Esthonyx, Cope, with Platycharops, Charlesworth, excited my interest, and requires a few words of comment. It is of the greatest importance to determine, if possible, the identity of generic and specific forms in widely separated localities during past geological ages. This has occasionally been successfully accomplished, as, for instance, the determination of Hyrachyus, by Gaudry, and of Oxyana, by Filhol, in France. In other cases discovery of missing parts has shown that such supposed identification were premature. 'I'hus, I have been compelled to recede from some identifications of American with European Lemuroids.

After an examination of Prof. Owen's figures and description of Miolophus planiceps ${ }^{1}$ cited by Mr. Lydekker, I find that the identity of Esthonyx with Miolophus is extremely improbable, and could as well be asserted of at least one other genus. Indeed, there is nothing in the technical characters of the superior molars to prevent the identification of Miolophus with Chriacus, Mioclaenus or Deltatherium, genera which only differ from each other in the characters of the superior and inferior premolars and inferior molars. But Esthonyx differs still more from the normal types in its very peculiar incisors. In order that Miolophus should be identified with Esthonyx under these circumstances, some evidence as to the characters of its incisors should be obtained, which is not the case as yet. Mr. Lydekker appears to attach some importance to a space behind p.m. 3. This space in the specimen of Esthonyx Burmeisteri figured by me, may be due to accident, as the maxillary bone is in bad condition, and a fissure traversed the first true inferior molar. There is also a good reason for suspecting that the genera in question are not identical. This is the presence of a loop-like inner posterior 1 Platycharops Richardsoni, teste Lydekker. 